\title{
GEOSPATIAL INFORMATION RELEVANT TO THE FLOOD PROTECTION AVAILABLE ON THE MAINSTREAM WEB
}

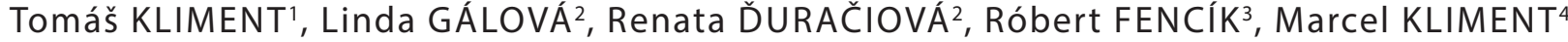

\section{Abstract}

Flood protection is one of several disciplines where geospatial data is very important and is a crucial component. Its management, processing and sharing form the foundation for their efficient use; therefore, special attention is required in the development of effective, precise, standardized, and interoperable models for the discovery and publishing of data on the Web. This paper describes the design of a methodology to discover Open Geospatial Consortium (OGC) services on the Web and collect descriptive information, i.e., metadata in a geocatalogue. A pilot implementation of the proposed methodology - Geocatalogue of geospatial information provided by OGC services discovered on Google (hereinafter "Geocatalogue") - was used to search for available resources relevant to the area of flood protection. The result is an analysis of the availability of resources discovered through their metadata collected from the OGC services (WMS, WFS, etc.) and the resources they provide (WMS layers, WFS objects, etc.) within the domain of flood protection.
Address

1 Institute for the Dynamics of Environmental Processes of the National Research Council of Italy, Via Mario Bianco, 9, 20131 Milan, Italy

2 Department of Theoretical Geodesy, Faculty of Civil Engineering, Slovak University of Technology in Bratislava, Radlinského 11, 813 68, Bratislava, Slovakia

3 Department of Mapping and Land Consolidation, Faculty of Civil Engineering, Slovak University of Technology in Bratislava, Radlinského 11,813 68, Bratislava, Slovakia

4 Department of Landscape Planning and Ground Design, Slovak University of Agriculture in Nitra, Tulipánová 7, 949 76, Nitra, Slovakia.

Corresponding author: tomas.kliment@gmail.com

\section{Keywords}

- Discovery,

- geospatial data,

- metadata,

- OGC services,

- geocatalogue,

- flood protection

\section{INTRODUCTION}

Nowadays, the World Wide Web (WWW) has a geospatial extent (Pellicer, 2011). Web pages use geospatial information (GI) in order to define the positional references of their information contents to the Earth. Web portals such as Google Maps use geospatial data from various areas (transportation networks, forestry, hydrography, etc.) produced by a variety of authoritative organizations (U.S. Department of Transportation, European Space Agency, Environmental Information Centre India, etc.). The ability of data producers and consumers related to the management of GI shapes the current geospatial web. The geo- spatial web can be defined as a collection of geospatial web services, geospatial data and metadata, which facilitate in the discovery, evaluation and use of geospatial data within a concrete area (natural hazards and disaster risk management, renewable energy resources, etc.).

Data used in flood risk management include hydrological data, environmental data, topographical data, land-use planning documentation, cadastral data, economic data, utility network data, statistical data, etc. (Gálová and Kliment, 2010). The availability of such data might improve the efficiency of resolving crisis situations. Geospatial data plays a significant role in such resolutions in that it has a more complex structure that non-spatial data and is characterized by a high 
level of heterogeneity in the data formats and models. In many cases several datasets may contain the same information but with different semantics of their attributes. Data collection, processing, and analysis radically affect time and cost needs for further handling within a concrete application. In order to improve the current state of this field, several processes need to be improved, including data discovery models, data harmonization, the development of appropriate methodologies for data analysis, and further processing as well as legislative support (Gálová, 2012).

\section{STATE OF THE ART}

Current legislation in the field of water management in the European Union (EU) is represented by Directive 2000/60/EC; however, lowering flood risks is not mentioned as one of its main objectives (EC, 2000). For this reason, the European Parliament and the European Council approved Directive 2007/60/EC on the assessment and management of flood risks, which is to be implemented across the EU member states. The directive imposes an obligation on member states through the responsible organizations to make publicly available the results of preliminary flood risk assessments (until the year 2011), flood hazard maps, and flood risk maps until 2013 through their web pages. Moreover, the first flood risk management plans and their actualisation must be approved by 2015 .

The main legislative framework related to the availability of public GI on the internet is Directive 2007/2/EC on Infrastructure for Spatial Information in Europe (INSPIRE), which aims at the establishment of an infrastructure for spatial information in Europe to support community environmental policies and policies or activities which may have an impact on the environment (INSPIRE, 2007). The INSPIRE infrastructure is based on the principles of a spatial data infrastructure (Nebert, 2009). Information resources relevant to the domain of flood protection may be represented by the INSPIRE data models for most of the themes defined in Annexes I-III of the directive. If some information needed is missing, the INSPIRE data models can be extended by specific features in order to fulfil the requirements (e.g., NatureSDIplus).

\subsection{Discovery of geospatial information on the web}

To discover specific information is an important function which any information system should support (Florczyk, 2012). Nowadays, the geospatial web provides different methods for discovering and accessing geospatial data. The three main methods are defined as follows: spatial browsing systems, Spatial Data Infrastructure (SDI) and on-line GIS (Pellicer, 2011).

In 1994, the Open Geospatial Consortium (formerly, the Open GIS Consortium or OGC) was established; it is a leader in the development of specifications for the definition of open standardized interfaces of web services to share GI resources on the Internet. The OGC specifications used to publish standardized geospatial services are the Web Map Service (WMS) (Wenjue et al., 2004), Web Feature Service (WFS) (Peng et al., 2004), Web Coverage Service (WCS) (Baumann, 2010), Web Processing Service (WPS) (Schut, 2007), Sensor Observation Service (SOS) (Oggioni et al., 2010), Catalogue Service for the Web (CSW) (Senkler et al., 2004) and Web Map Tile Service (WMTS) (Masó et al., 2010). Some of the above-mentioned OGC specifications have already become ISO standards (e.g., ISO 19128 Geographic information - Web map server interface (ISO, 2005), ISO 19142 Geographic information -- Web Feature Service (ISO, 2010), etc.)

Applications known as geocatalogues, which are implemented within an SDI realization, are currently used to discover GI resourc-

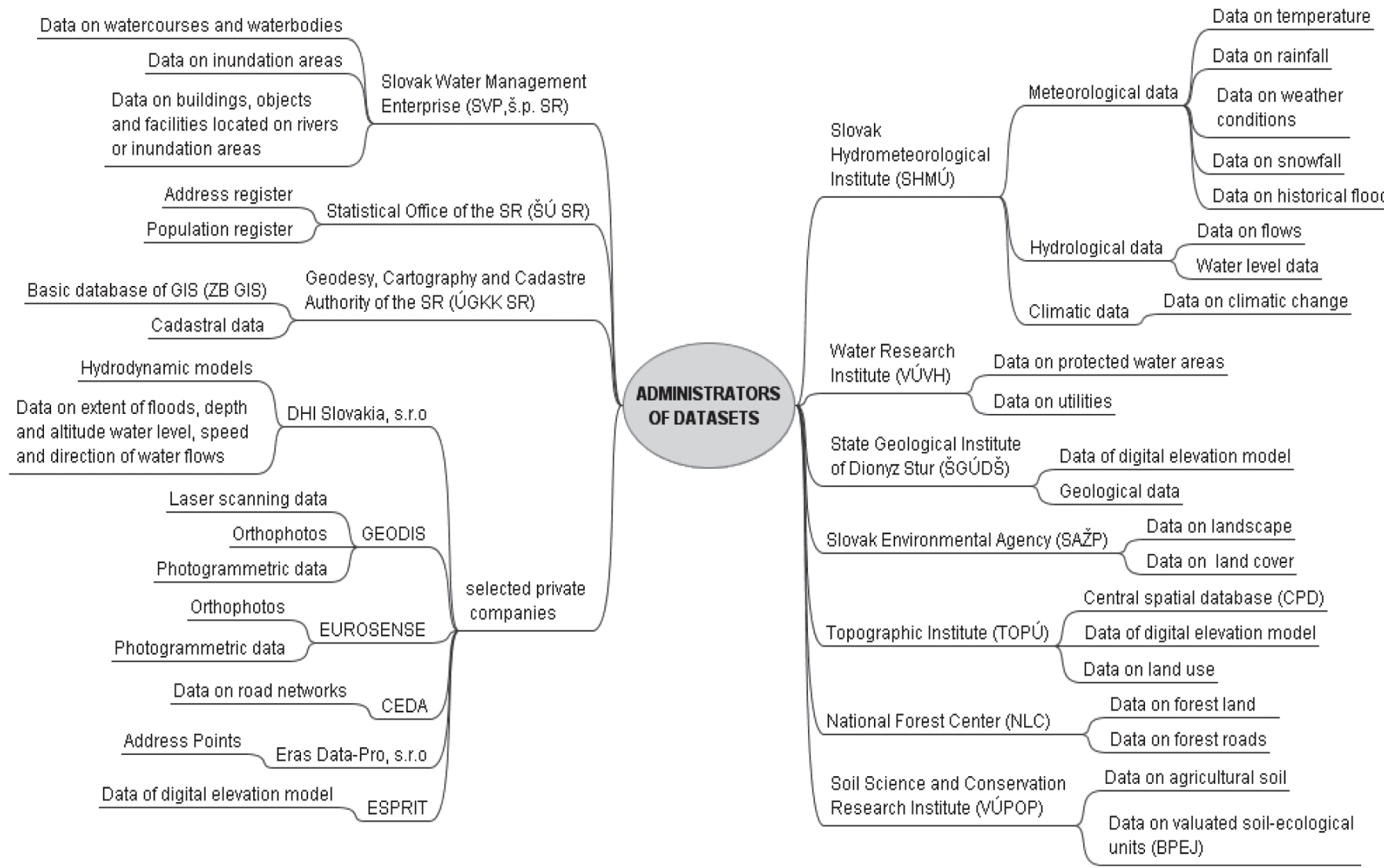

Fig. 1 The scheme of the providers and the geospatial datasets relevant to flood protection (Gálová and Kliment, 2010). 
es defined by the OGC specifications on the internet. The providers of geospatial data and services have to document them by metadata, which have a predefined structure, and publish the metadata through the geocatalogue. Therefore, there is often a duplication of information already contained in the original GI resources. An alternative solution to the geocatalogue may be internet search engines (SE) under certain conditions (Kliment, 2012). SE does not require any extra work, and as the current research (Wenven et al., 2010; Pellicer, 2011; Kliment, 2012) shows, they provide considerable opportunities for the discovery of GI resources with a properly designed methodology.

Despite the facts described above, when ordinary users browse the web and search for information that should have a spatial localization, such as a specific address in Bratislava or pictures of the Krásna Hôrka castle and its surroundings, they would not use either an on-line GIS application or an application within SDI. They would rather use, for example, Google Maps or the free wiki world map OpenStreetMap or a website which has incorporated these applications. Those applications provide functionality for spatial browsing. They combine spatial queries with an interactive display of the digital maps in such a way that it is possible for the user to explore the spatial dimensions of one or more information systems (Larson, 1996). This system could use the standard web services (e.g., WMS and WFS) for the displaying of and access to spatial data stored in a remote GIS. It is important to point out that the systems of spatial browsing most used on the web (e.g., Google Maps) use proprietary specifications, which come from their original concept. These systems are being developed for widespread use and take into account the limitations and dynamics which are specific only in the context of the web. The possibility of their use within external applications is enabled by using the specific application programming interfaces (API) that they provide under certain licensing conditions. This fact allows for the development of new applications for spatial browsing that are built on these existing systems. This application is called a "geo mashup" (Schleidt et al., 2010). More details about these methods are described in (Kliment, 2012).

\subsection{Overview of geospatial data relevant to the flood protection domain}

Based on the analysis of data resources in the Slovak Republic (SR), we identified providers of datasets and related data themes, which were divided into governmental or private companies (Fig. 1). These bodies are collecting and providing the GI resources relevant to the field of flood protection.

\subsection{Current possibilities for discovering information on the web relevant to flood protection}

There are currently a number of initiatives, projects or operating portals for publishing GI sources related to flood issues. Below is an overview of the existing portals that are publishing relevant data for solving flood situations on global, European and national levels.

On the global level, systems and portals such as the GEO (http:// www.geoportal.org), Natural Disasters (http://www.naturaldisastersnews.net/), Humanitarian Early Warning Service (http://www. hewsweb.org/floods/) portals, and the Emergency Management Service (http://portal.ems-gmes.eu/frontend/gio-ems-mapping.html) a mapping portal within the Copernicus programme - and the Global Risk Data Platform geoportal (http://preview.grid.unep.ch/) are operating based on the principles of SDI. From the domain of flood protection, the Global Flood Map mapping portal is remarkable (http://globalfloodmap.org/) (Fig. 2); it uses NASA satellite data to portray areas of the world that are underwater and at risk of flooding if ocean levels rise.

On the European level, systems and portals such as the INSPIRE Geoportal (http://inspire-geoportal.ec.europa.eu/), the EUROGEOSS system (http://www.eurogeoss-broker.eu/) and the Transnational Internet Map Information System (http://webgis.timisflood.net/) operate based on the principles of SDI. The European Floods Portal (http://floods.jrc.ec.europa.eu/), which provides information on on-going floods, is based on the principle of on-line GIS. The portal of the European Environment Agency (http://www.eea.europa.eu)

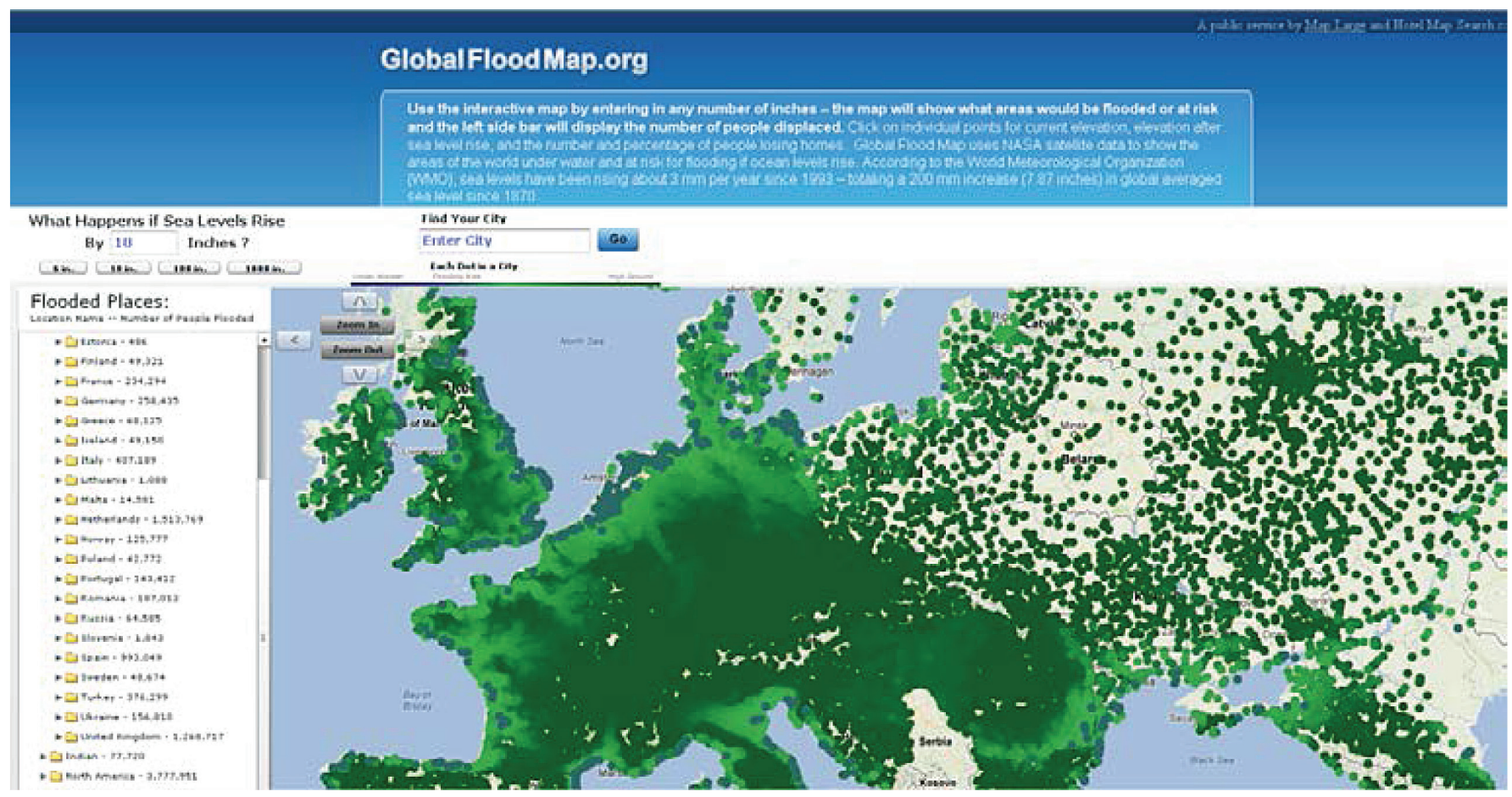

Fig. 2 Global Flood Map portal (http://globalfloodmap.org/). 
provides information on the environment. The Eye on Earth portal (http://eyeonearth.org), which is based on the principles of online GIS, allows for the publishing and sharing of information on the environment with a geo-spatial content. The new Danube Floodrisk Map portal (http://maps.danube-floodrisk.eu/) is very interesting; it provides information on flood risks in the catchment area of the Danube River (Fig. 3).

Portals and systems at the national level that publish GI resources related to floods include, for example, the Swiss geoportal (http:// map.geo.admin.ch/). It provides access to 35 different thematic levels of spatial data clearly available through the geocatalogue. The Polish national geoportal (http://geoportal.gov.pl) publishes data levels containing flood risk areas. Both of them are based on SDI principles. The on-line flood maps of Ireland are published on the website of the National Flood Hazard Mapping (http://www.floodmaps.ie/View/Default.aspx). Furthermore, on-line flood maps of the United Kingdom are available on the website of the Environment Agency (http://www.environment-agency.gov.uk/homeandleisure/ floods/31650.aspx). The interactive flood maps of Belgium are published on the Watertoets en overstromingskaarten portal (http:// geo-vlaanderen.gisvlaanderen.be/geo-vlaanderen/overstromingskaarten/). The portal of the Natural Hazard Overview and Risk Assessment Austria (http://www.hora.gv.at/) provides information on warnings of crisis situations in Austria. The flood plans of individual regions of the Czech Republic are published on a website (http:// www.dppcr.cz/) through WMS (Fig. 4).

The flood hazard maps and flood risk maps have not yet been published on the web in the SR. Only basic information is published through web portals such as the portal of the Slovak Hydrometeorological Institute (www.shmu.sk), the portal of the Slovak Water Management Enterprise (www.svp.sk), the Geoportal of the Slovak Environmental Agency (geoportal.sazp.sk/web/guest/), the Geoportal of Geodesy, Cartography and Cadastre Authority of the
SR (http://www.geoportal.sk/gp/), and the Enviroportal (www.enviroportal.sk).

An overview of the national hydrological and hydro-meteorological services in Europe is shown in Table 1 (http://www.wmo.int/ pages/members/membership/nhs_en.html).

\section{MATERIALS AND METHODOLOGY}

\subsection{Publishing OGC services discovered on the mainstream web in an SDI catalogue}

In this chapter, we describe a methodology (Kliment et al., 2013) for publishing OGC services discovered on the Web in a CSW-compliant geospatial catalogue. Figure 5 shows the five main steps of the workflow, which implements the proposed methodology. In order to support the individual steps, the following available tools were used: Google Search Client (step 1), OutWit Hub (step 1), GeoNetwork opensource (steps 4 and 5), MySQL database management system (steps 2-4) and Apache HTTP Server (steps 2-4), which were used to run the PHP scripts developed (import.php, crawl.php and harvesting.php).

In particular, the individual steps shown in Figure 5 may be summarized as follows (Kliment et al., 2013).

\section{1) Discover OGC services GetCapabilities URL addresses in Google $\mathrm{SE}$}

A Google search client was used as a search interface to discover available OGC service endpoints. The advanced search operator inurl was used for the query definition in order to restrict searching for predefined query strings in the URLs of the records stored in the Google database. An example of a query definition used to discover the WMS services GetCapabilities URLs was as follows: inurl:service $=$ WMS inurl:request $=$ GetCapabilities

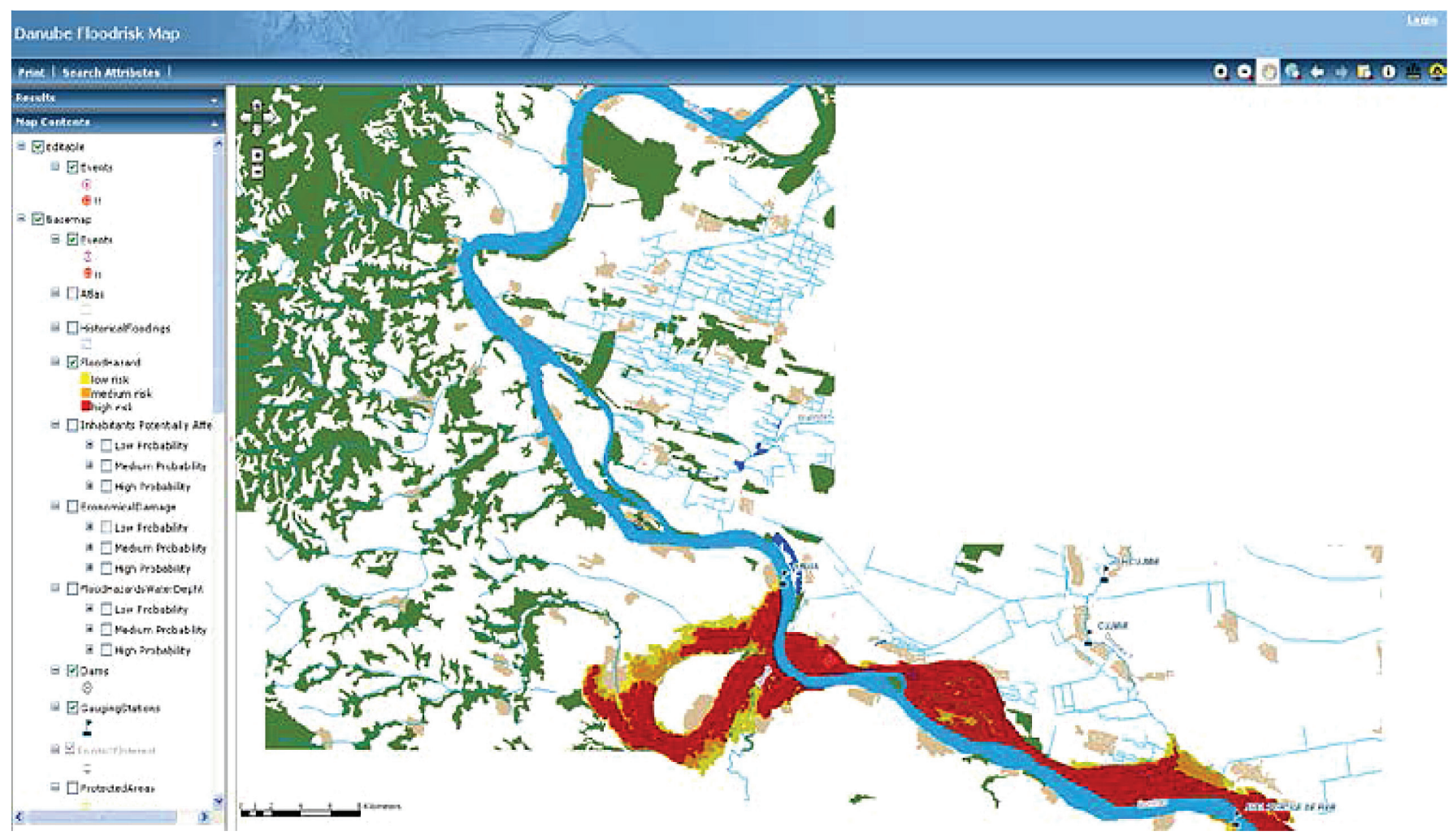

Fig. 3 Danube Floodrisk Map portal (http://maps.danube-floodrisk.eu/). 
Tab. 1 Overview of the national hydrological and hydro-meteorological services in Europe.

\begin{tabular}{|c|c|}
\hline Austria & Abteilung Wasserhaushalt, http://www.lebensministerium.at/wasser \\
\hline Belarus & Department of Hydrometeorology, http://www.pogoda.by/ \\
\hline Belgium & Institut Royal Météorologique, http://www.meteo.be/meteo/view/en/65239-Home.html \\
\hline Bulgaria & National Institute of Meteorology and Hydrology, http://www.meteo.bg/ \\
\hline Czech Republic & Czech Hydrometeorological Institute, http://old.chmi.cz/indexe.html \\
\hline Finland & Finnish Environment Institute (SIKE), http://www.ymparisto.fi/default.asp?node=5297\&lan=EN \\
\hline France & $\begin{array}{l}\text { Service Central d'Hydrométéorologie et d'Appui à la Prévision des Inondations (SCHAPI) } \\
\text { http://www.reseau.eaufrance.fr/acteur/schapi }\end{array}$ \\
\hline Germany & Federal Institute of Hydrology, http://www.ihp-germany.de/_home/home_node.html \\
\hline Hungary & VITUKI, http://www.vituki.hu/ \\
\hline Luxembourg & Administration de la Gestion de l'Eau, http://www.eau.public.lu/ \\
\hline Netherlands & Rijkswaterstaat Waterdienst, http://www.rijkswaterstaat.nl/water/ \\
\hline Norway & Norwegian Water Reresources and Energy Directorate (NVE), http://www.nve.no/en/ \\
\hline Poland & Institute of Meteorology and Water Management, http://www.imgw.pl/index.php \\
\hline Portugal & Instituto da Agua, http://www.inag.pt/ \\
\hline Romania & National Institute of Hydrology and Water Management, http://www.hidro.ro/ \\
\hline Russian Federation & Federal Service for Hydrometeorology and Environmental Monitoring, http://www.meteorf.ru/en_default.aspx \\
\hline Serbia & Republic Hydrometeorological Service of Serbia, http://www.hidmet.gov.rs/index_eng.php \\
\hline Slovakia & Slovak Hydrometeorological Institute, http://www.shmu.sk \\
\hline Slovenia & Hydrology and State of the Environment Office, http://www.arso.gov.si/ \\
\hline Sweden & Swedish Meteorological and Hydrological Institute (SMHI), http://www.smhi.se/en \\
\hline Switzerland & $\begin{array}{l}\text { Federal Office for Water and Geology, Swiss National Hydrological Survey } \\
\text { http://www.hydrodaten.admin.ch/en/index.html?lang=en }\end{array}$ \\
\hline Ukraine & State Committee for Hydrometeorology, http://meteo.ua/ \\
\hline \begin{tabular}{|l|} 
United Kingdom of Great \\
Britain and Northern Ireland
\end{tabular} & Centre for Ecology \& Hydrology, http://www.ceh.ac.uk/ \\
\hline
\end{tabular}



Fig. 4 Portal of the flood plans of the Czech Republic (http://www.dppcr.cz/). 




Fig. 5 Methodology overview (Kliment et al., 2013).

The same pattern was used for all seven types of OGC services, which we were searching for with the standardized acronyms as follows: WFS, WCS, SOS, WPS, CSW and WMTS. Information such as Title, Description and URL for each type of the OGC service were extracted from the results list and converted into the individual comma-separated value files (e.g., wms.csv, wfs.csv, sos.csv, etc.). These $\operatorname{csv}$ files were used as inputs for the next step in the implemented workflow.

\section{2) Populate a database with discovered URL addresses}

A MySQL database was created as a central storage for discovered OGC service endpoints (GetCapabilities URL addresses). In order to populate the database, a PHP script import.php was developed. The script retrieves URL addresses from $c s v$ files created in Step 1 and populates predefined columns in the database with parsed URL addresses and related information, such as title and description.

\section{3) Verify OGC services endpoints}

The objective of this step was to verify whether the services found are functioning. In order to implement this step, another PHP script crawl.php was developed. The script fetches a GetCapabilities URL stored in the database (Step 2), triggers it (sends the GetCapabilities request) and verifies the availability of the service. If the service is available, the script extracts the relevant information (e.g., version, etc.) to update the corresponding table columns. Once the validation script is finished, each record of the resulting database contains an URL pointing to the GetCapabilities method of the OGC service together with the additional information (version and status) necessary for the next step.
4) Add and run harvesting tasks in a GeoNetwork opensource for OGC services discovered

The GeoNetwork opensource catalogue was used as a central repository for ISO 19115/19119 metadata harvested from OGC services discovered (WMS, WFS, WCS, WFS, SOS and CSW) and the GI resources (WMS Layers, WFS Features, WCS Coverages, SOS Observations and CSW datasets, series and services) that they publish. Harvesting tasks were created and run for all the OGC service endpoints stored and verified in the previous Step 3. Harvesting XML services (xml.harvesting.get, xml.harvesting. add and xml.harvesting.run) provided by GeoNetwork API were used to manage the harvesting task in a programmatic way with a third developed PHP script harvesting.php through HTTP POST messages. This script searches for services for which the version was detected (they have the value "available" in the column status) and creates harvesting tasks in the GeoNetwork. Two types of harvesting tasks have been defined: The first one is for catalogue services - csw (for records that have the stored value $c s w$ in the column type), and the second one is for other OGC services such as WMS, WFS, WCS, WPS and SOS ogcwxs (other acronyms stored in the column type).

\section{5) Publish metadata through an SDI catalogue}

The GeoNetwork opensource has also been used as a client application to provide a web-based search interface on the metadata harvested in the previous step as well as a map client to portray layers from the WMS services discovered. Figure 6 shows the customized GUI of the GeoNetwork opensource, version 2.8.0 RC0, deployed in September 2012.

The discovery component (left side of Figure 6) provides a simple (full text) and advanced search query definition, which provides spatial and temporal thematic query definitions. The view client (right 


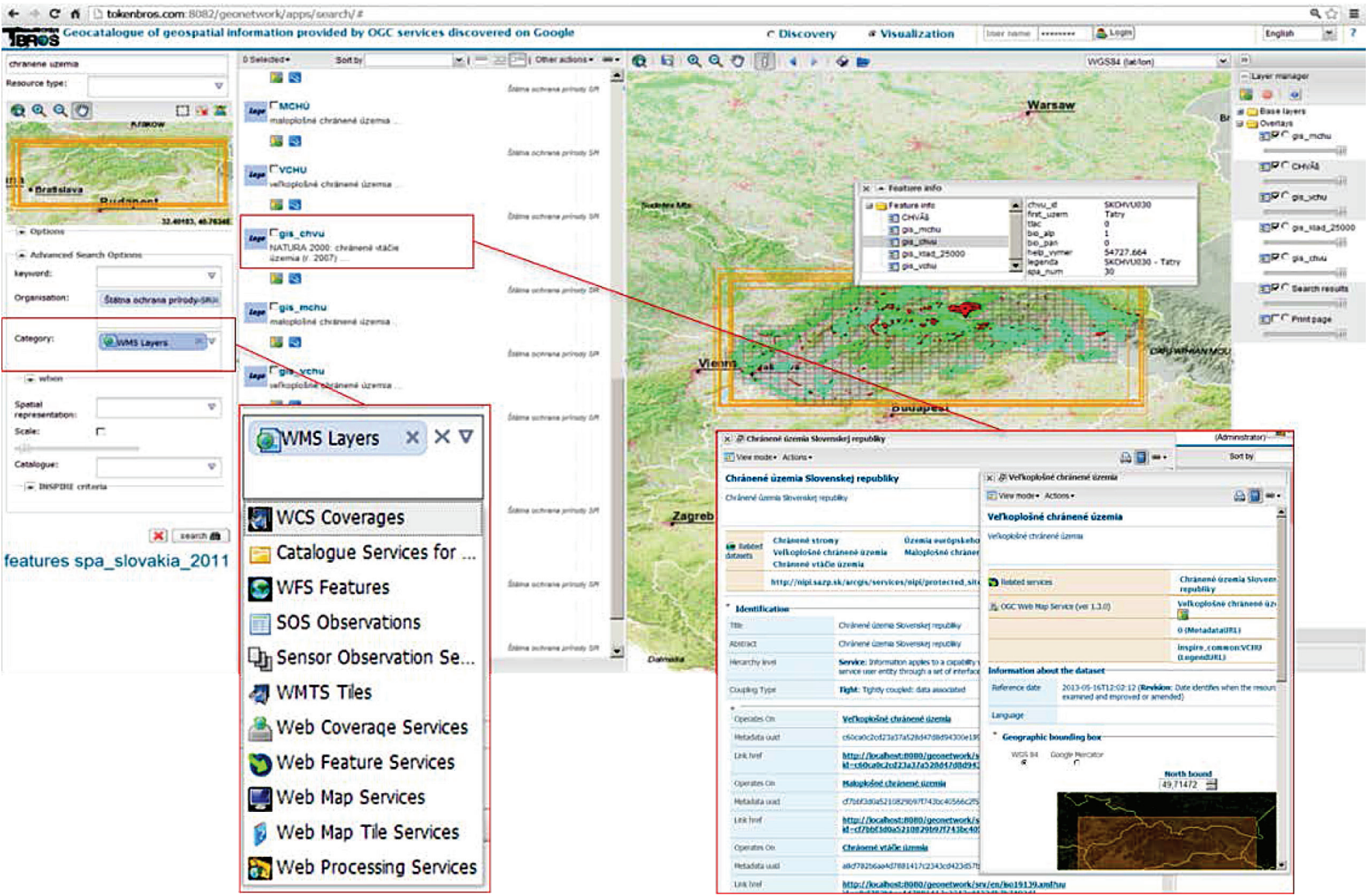

Fig. 6 Discovery and view of geospatial information provided by OGC services in the GeoNetwork opensource.

side of Figure 6) communicates directly with remote WMS services in order to portray the layers on a map (operation GetMap) and retrieve additional information about features (operation GetFeatureInfo).

\subsection{Availability of geospatial information relevant to flood protection}

We have used the Geocatalogue (Kliment, 2012) to search for GI resources relevant to flood protection through the metadata har- vested from OGC services discovered on Google SE (Tab. 2) as well as through metadata available on the INSPIRE Geoportal discovery client (http://inspire-geoportal.ec.europa.eu/discovery/).

Based on our analysis of the INSPIRE themes, we defined the following keywords used for our sample searches: River*, Flood*, Flood Map, Flood Risk, Hydro* (* represents any text string for a base word).

Tab. 2 Numbers of OGC services GetCapabilities URLs discovered on Google SE (Kliment, 2013).

\begin{tabular}{|c|c|c|c|c|c|c|}
\hline $\begin{array}{c}\text { OGC SERVICE } \\
\text { TYPE }\end{array}$ & $\begin{array}{c}\text { JUNE } \\
\mathbf{2 0 1 2}\end{array}$ & $\begin{array}{c}\text { JULY } \\
\mathbf{2 0 1 2}\end{array}$ & $\begin{array}{c}\text { AUGUST } \\
\mathbf{2 0 1 2}\end{array}$ & $\begin{array}{c}\text { NOVEMBER } \\
\mathbf{2 0 1 2}\end{array}$ & $\begin{array}{c}\text { JANUARY } \\
\mathbf{2 0 1 3}\end{array}$ & $\begin{array}{c}\text { DATABASE } \\
\mathbf{2 8 / 0 1 / 2 0 1 3}\end{array}$ \\
\hline WMS & $554 / 541$ & $540 / 527$ & $725 / 711$ & $699 / 686$ & $752 / 738$ & $1536 / 1433$ \\
\hline WFS & $530 / 517$ & $520 / 509$ & $636 / 620$ & $619 / 604$ & $591 / 575$ & $1282 / 1115$ \\
\hline WCS & $169 / 162$ & $176 / 171$ & $251 / 245$ & $356 / 347$ & $231 / 226$ & $632 / 589$ \\
\hline WPS & $86 / 77$ & $86 / 78$ & $94 / 88$ & $90 / 87$ & $95 / 91$ & $136 / 112$ \\
\hline SOS & $71 / 56$ & $71 / 55$ & $76 / 65$ & $72 / 58$ & $74 / 58$ & $100 / 85$ \\
\hline CSW & $178 / 169$ & $142 / 132$ & $177 / 166$ & $164 / 160$ & $178 / 175$ & $281 / 244$ \\
\hline WMTS & $157 / 156$ & $169 / 168$ & $151 / 149$ & $190 / 190$ & $198 / 198$ & $361 / 277$ \\
\hline
\end{tabular}




\section{RESULTS AND DISCUSSION}

The results are an analysis of the availability of GI resources (Tab. 3) based on the quantity of collected metadata records describing the following GI resource types: Datasets, Series and Services harvested from CSW services. Moreover, they include metadata harvested from the following geospatial web services: WMS, WFS, WCS, WPS, SOS, and the content they provide: WMS Layers, WFS Features, WCS Coverages and SOS Observations. The practical use of the proposed pilot in the domain of flood protection provides access to GI resources in several ways: through the web interface of the GeoNetwork geocatalogue populated by metadata extracted from OGC services discovered in Google, by a simple (full text) search or through an advanced search (Keywords, Organizations, Temporal and Spatial search, etc.). The solution also enables categorizing the results by the type of OGC service and the type of geospatial data representation. Moreover, it provides a client view to portray data from WMS in the map viewer, display detailed metadata, and

Tab. 4 Relevant GI resources available in the INSPIRE Geoportal (http://inspire-geoportal.ec.europa.eu), actual to18.03.2013.

\begin{tabular}{|l|c|c|c|c|}
\hline & \multicolumn{3}{|c|}{$\begin{array}{c}\text { OGC CSW } \\
\text { dataset/series/service }\end{array}$} & $\begin{array}{c}\text { WMS } \\
\text { Layers }\end{array}$ \\
\hline river* & 107 & 3 & 25 & 12 \\
River* & 80 & 4 & 16 & 20 \\
\hline flood* & 27 & 2 & 12 & 4 \\
Flood* & 29 & 1 & 9 & 6 \\
\hline flood map & 3 & 0 & 0 & 0 \\
Flood map & 0 & 0 & 0 & 0 \\
Flood Map & 6 & 0 & 4 & 5 \\
\hline flood risk & 4 & 0 & 0 & 0 \\
Flood risk & 11 & 0 & 0 & 0 \\
Flood Risk & 2 & 0 & 2 & 0 \\
\hline hydro* & 1291 & 55 & 165 & 240 \\
Hydro* & 3839 & 103 & 291 & 820 \\
\hline
\end{tabular}

integrate remote services to the external GIS applications (ArcGIS, Quantum GIS, etc.). The absolute result is a comparison of the availability of GI resources relevant to the domain of flood protection between the pilot implementation of the methodology (Kliment, 2012) (Tab. 3) and a standard SDI catalogue solution provided by the INSPIRE Geoportal (Tab. 4).

One difficulty of the current INSPIRE Geoportal implementation which we discovered is the need to differentiate the uppercase and lowercase letters (case sensitivity) in the query and also the diacritics in the text strings, which complicate the overall search process for the relevant data.

The Geocatalogue implemented by the proposed methodology provides more sophisticated discovery capabilities through the user-friendly interface, which is reflected in the data discovery by the defined keywords, but also by the names and acronyms of the organizations that are managing data from the relevant domain in Europe (Tab. 1).

Further analysis will be carried out on the metadata harvested from the OGC service discovered in order to provide a more accurate overview of the number of OGC services that are not registered in the available CSWs as the next step. Moreover, a qualitative analysis of the OGC services discovered and their content such as in Ardielli et al., 2012, or Horak et al., 2013, with a suitable methodology (Kliment et al., 2012) will have to be performed in order to define whether such information may or may not be used in the domain of flood protection.

\section{CONCLUSIONS}

A flood protection area should be understood as a required component of the integrated and complex management of interactive activities in whole river basins. Therefore, any effort to improve flood protection in an international context leads to the harmonization of the heterogeneous data resources of that domain, thus increasing the level of interoperability.

The proposed methodology to discover GI resources on the mainstream web implemented by the Geocatalogue provides a unified interface with global coverage, which enables the discovery of a larger number of GI resources relevant to the flood protection domain in comparison with the standard catalogue solution (e.g., INSPIRE Geoportal). From the metadata provided it is possible to perform further investigations through the organizations providing

Tab. 3 Available relevant GI resources in the Geocatalogue (http://tokenbros.com:8082/geocatalogue, actual to 18.03.2013).

\begin{tabular}{|c|c|c|c|c|c|c|c|c|c|c|c|c|}
\hline & \multicolumn{3}{|c|}{$\begin{array}{c}\text { OGC CSW } \\
\text { dataset/series/service }\end{array}$} & \multirow{2}{*}{$\sum_{374}^{n}$} & \multirow{2}{*}{ 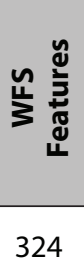 } & \multirow{2}{*}{ 荇 } & \multirow{2}{*}{ 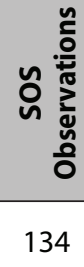 } & \multirow{2}{*}{$\begin{array}{l}\tilde{y} \\
3\end{array}$} & \multirow{2}{*}{$\sum_{54}^{n}$} & \multirow{2}{*}{$\begin{array}{l}\frac{n}{3} \\
55\end{array}$} & \multirow{2}{*}{$\frac{n}{3}$} & \multirow{2}{*}{$\begin{array}{l}\text { ๕ั } \\
\text { ڤ } \\
5\end{array}$} \\
\hline River* & 5420 & 25 & 49 & & & & & & & & & \\
\hline Flood* & 2404 & 8 & 16 & 137 & 151 & 32 & 0 & 3 & 26 & 37 & 0 & 1 \\
\hline Flood Map & 277 & 7 & 9 & 104 & 25 & 2 & 0 & 0 & 14 & 13 & 0 & 0 \\
\hline Flood Risk & 181 & 0 & 6 & 24 & 2 & 0 & 0 & 0 & 2 & 2 & 0 & 0 \\
\hline Hydro* & 9607 & 210 & 381 & 1493 & 402 & 4 & 16 & 4 & 85 & 61 & 6 & 2 \\
\hline
\end{tabular}


relevant data and in such a way to find more relevant GI resources on a narrower level, such as, national, organisational, etc.

The issue of floods is still and will remain a very important topic for the future. Global warming, which causes climate change on the continents, increases the risk of floods and related flood damage.
Because this damage is enormous and often unquantifiable, the possibility of its early prevention or elimination through the availability of information on floods could bring significant saving of funds, but mainly help to protect human lives and the environment.

\section{REFERENCES}

Ardielli, J. - Horák, J. - Ružička, J. (2012) View Service Quality Testing according to INSPIRE Implementing Rules. Electronics and Electrical Engineering, 119.3: 69-74.

Baumann, P. (2010) OGC WCS 2.0 interface standard-core. Open Geospatial Consortium Inc. Wayland, MA, USA, OpenGIS ${ }^{\circledR}$ Interface Standard OGC.

Florczyk, A. J. (2012) Search improvement within the geospatial web in the context of spatial data infrastructures. PhD Thesis, Universidad de Zaragoza.

Gálová, L. - Kliment, T. (2010) Heterogénne dáta v povodňovom krizovom managemente (Heterogeneous Data in Flood Crisis Management). Pedagogické listy 16: Geodetická a kartografická podpora protipovodňovej ochrany, Bratislava: Slovak University of Technology in Bratislava, Slovak Republic, pp. 40-50, ISBN 978-80-227-3424-0 [in Slovak].

Gálová, L. (2012) Návrh konceptuálneho modelu pre riešenie povodňových krizových situácií v súlade so smernicou INSPIRE (Draft of conceptual model for solving flood crisis situations in accordance with the INSPIRE directive). In: Juniorstav 2012. Brno University of Technology, Brno, Czech Republic, 13 pp., ISBN 978-80-214-4293-8 [in Slovak].

Horak, J - Ruzicka, J. - Ardielli, J. (2013) Výkonové a zátěžové testy stahovacich služeb ČUZK dle požadavků INSPIRE (Performance and Stress Tests of Download Services of COSMC according to INSPIRE). Zborník sympózia. Ostrava, ČR, 23.-26.1.2011. Ostrava: VŠB-Technická univerzita Ostrava, 2013, p. 9. ISBN 978-80-248-2951-7 [in Czech].

International Organization for Standardisation (2005) ISO 19128:2005. Geographic information - Web Map Server Interface.

International Organization for Standardisation (2010). ISO 19142:2010. Geographic information - Web Feature Service.

Kliment, T. - Granell, C. - Cetl, V. - Kliment, M. (2013) Publishing OGC resources discovered on the mainstream web in an SDI catalogue. In Agile 2013- 16th AGILE International Conference on Geographic Information Science, Leuven, Belgium.

Kliment, T. - Tuchyňa, M. - Cibulka, D. - Kliment, M. - Michnová, Z. (2012) Testovanie interoperability v oblasti geopriestorových informácii (Interoperability testing in the geospatial information domain). Enviromagazín, Vol.17, No. 5, pp. 12-13, ISSN 1335-1877 [in Slovak].

Kliment, T. - Tuchyňa, M. - Kliment, M. (2012). Methodology for conformance testing of spatial data infrastructure components including an example of its implementation in Slovakia. Slovak Journal of Civil Engineering. Volume XX, No. 1, pp. 10-20, ISSN 1338-3973

Kliment, T. (2012) Vyhl'adávanie zdrojov geopriestorových informácii prostrednictvom internetu (Geospatial information resources discovery on the Internet). $\mathrm{PhD}$ thesis, Bratislava: Slovak University of Technology in Bratislava, Faculty of Civil Engineering, Department of Theoretical Geodesy [in Slovak].

Larson, Ray R. (1996) Geographic information retrieval and spatial browsing. GIS and libraries: patrons, maps and spatial information, 1996, 81-124.

Masó, J. - Pomakis, K. - Julia, N. (2010) OGC Web Map Tile Service (WMTS). Implementation Standard. Ver., 1.

Oggioni, A. - Carrara, P. - Pepe, M. - Manca, D. - Giardino, C. - Criscuolo, L. (2010) Sustainable water management: an operative test for monitoring lakes through integrated Earth sensing. $3^{\text {rd }}$ ISDE Digital Earth Summit, 12-14 June, 2010, Nessebar, Bulgaria.

Pellicer, F. J. L. (2011) Semantic linkage of the invisible geospatial web. PhD Thesis. Universidad de Zaragoza.

Peng, Z.-R. - Zhang, Ch. (2004) The roles of geography markup language (GML), scalable vector graphics (SVG), and Web feature service (WFS) specifications in the development of Internet geographic information systems (GIS). Journal of Geographical Systems, 6.2: 95-116.

Schleidt, K. - Koška, M. - Mozolík, P. - Pratschner, B. (2010) INSPIRE Biodiversity Mashup. INSPIRE conference 2010. 22-25 June 2010, Cracow, Poland.

Schut, P. (2007) OGC Web Processing Service (WPS) version 1.0.0. OGC Standard Document. Open Geospatial Consortium.

Senkler, K. - Voges - U. - Remke, A. (2004) An ISO 19115/19119 profile for $O G C$ catalogue services $C S W$ 2.0. Workshop paper presented at 10th EC-GI \& GIS Workshop, Warsaw, Poland.

Wenjue, J, - Yumin, Ch. - Jianya, G. (2004) Implementation of OGC web map service based on web service. Geo-spatial Information Science, 7.2: 148-152.

Wenven, L. - Chaowei, Y. - Chngjun, Y. (2010) An active crawler for discovering geospatial web services and their distribution pattern - a case study of OGC Web Map Service. International Journal of Geographical Information Science, Vol. 24, No. 8, pp. 1127-47. 


\section{Internet resources}

Apache HTTP Server - http://httpd.apache.org/

EuroGEOSS - www.eurogeoss.eu

Geocatalogue of geospatial information provided by OGC services discovered on Google - http://tokenbros.com:8082

Geonetwork harvesting services - http://www.geonetwork-opensource.org/manuals/trunk/developer/xml_services/services_harvesting.html
GeoNetwork opensource - http://geonetwork-opensource.org/

Google Search Client - https://www.google.com

MySQL DBMS - http://www.mysql.com/

NatureSDIplus - http://www.nature-sdi.eu/

Open Geospatial Consortium - www.opengeospatial.org

OutWit Hub - http://www.outwit.com/

PHP - http://php.net/ 